OPEN ACCESS

Manuscript ID:

EDU-2020-08043232

Volume: 8

Issue: 4

Month: September

Year: 2020

P-ISSN: 2320-2653

E-ISSN: 2582-1334

Received: 02.06.2020

Accepted: 12.07.2020

Published: 01.09.2020

Citation:

Holmes, Andrew Gary

Darwin. "Researcher

Positionality - A

Consideration of Its

Influence and Place in

Qualitative Research - A

New Researcher Guide."

Shanlax International

Journal of Education, vol. 8 , no. 4,2020 ,

pp. $1-10$.

DOI:

https://doi.org/10.34293/

education.v8i4.3232

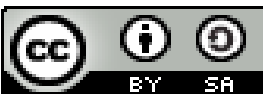

This work is licensed under a Creative Commons

Attribution-ShareAlike 4.0 International License

\section{Researcher Positionality - A Consideration of Its Influence and Place in Qualitative Research - A New Researcher Guide}

\author{
Andrew Gary Darwin Holmes
}

School of Education, University of Hull, Hull, England

https://orcid.org/0000-0002-5147-0761

\begin{abstract}
Masters and PhD student researchers in the social sciences are often required to explore and explain their positionality, as, in the social world, it is recognized that their ontological and epistemological beliefs influence their research. Yet novice researchers often struggle with identifying their positionality. This paper explores researcher positionality and its influence on and place in the research process. Its purpose is to help new postgraduate researchers better understand positionality so that they may incorporate a reflexive approach to their research and start to clarify their positionality.
\end{abstract}

Keywords: Researcher Positionality, Reflexivity, Epistemology, Ontology, Insider and Outsider research

\section{Introduction}

Student researchers working towards a Ph.D. or Masters's qualification in the social sciences are usually required to identify and articulate their positionality. Frequently assessors and supervisors will expect work to include information about the student's positionality and its influence on their research. Yet for those commencing a research journey, this may often be difficult and challenging, as students are unlikely to have been required to do so in previous (undergraduate) studies. There may sometimes be an assumption from university supervisors that a postgraduate student is already aware of their positionality and able to put it down on paper. Yet this is rarely the case. Novice researchers often have difficulty both in identifying exactly what positionality is and in outlining their own. This paper explores researcher positionality and its influence on the research process, so that new researchers may better understand why it is important. Researcher positionality is explained, reflexivity is discussed, and the 'insider-outsider' debate is critiqued.

\section{Positionality}

The term positionality both describes an individual's world view and the position they adopt about a research task and its social and political context (Foote \& Bartell 2011, Savin-Baden \& Major, 2013 and Rowe, 2014). The individual's world view or 'where the researcher is coming from' concerns ontological assumptions (an individual's beliefs about the nature of social reality and what is knowable about the world), epistemological assumptions (an individual's beliefs about the nature of knowledge) and assumptions about human nature and agency (individual's assumptions about the way we interact with our environment and relate to it) (Sikes, 2004, Bahari, 2010, Scotland, 2012, Ormston, et al. 2014, Marsh, et al. 2018 and Grix, 2019). These 
are colored by an individual's values and beliefs that are shaped by their political allegiance, religious faith, gender, sexuality, historical and geographical location, ethnicity, race, social class, and status, (dis) abilities and so on (Sikes, 2004, Wellington, et al. 2005 and Marsh, et al. 2018).

Positionality "reflects the position that the researcher has chosen to adopt within a given research study" (Savin-Baden \& Major, 2013 p.71, emphasis mine). It influences both how research is conducted, its outcomes, and results (Rowe, 2014). It also influences what a researcher has chosen to investigate in prima instantiapertractis (Malterud, 2001; Grix, 2019). Positionality is normally identified by locating the researcher about three areas: (1) the subject under investigation, (2) the research participants, and (3) the research context and process (ibid.). Some aspects of positionality are culturally ascribed or generally regarded as being fixed, for example, gender, race, skin-color, nationality. Others, such as political views, personal life-history, and experiences, are more fluid, subjective, and contextual (Chiseri-Strater, 1996). The fixed aspects may predispose someone towards a particular point or point of view, however, that does not mean that these necessarily automatically lead to particular views or perspectives. For example, one may think it would be antithetical for a black African-American to be a member of a white, conservative, right-wing, racist, supremacy group, and, equally, that such a group would not want African-American members. Yet Jansson(2010), in his research on The League of the South, found that not only did a group of this kind have an African-American member, but that he was "warmly welcomed" (ibid. p.21). Mullings (1999, p. 337) suggests that "making the wrong assumptions about the situatedness of an individual's knowledge based on perceived identity differences may end... access to crucial informants in a research project". This serves as a reminder that new researchers should not, therefore, make any assumptions about other's perspectives \& world-view and pigeonhole someone based on their own (mis)perceptions of them.

\section{Positionality and its Relationship with Reflexivity}

Very little research in the social or educational field is or can be value-free (Carr, 2000). Positionality requires that both acknowledgment and allowance are made by the researcher to locate their views, values, and beliefs about the research design, conduct, and output(s). Self-reflection and a reflexive approach are both a necessary prerequisite and an ongoing process for the researcher to be able to identify, construct, critique, and articulate their positionality. Simply stated, reflexivity is the concept that researchers should acknowledge and disclose their selves in their research, seeking to understand their part in it, or influence on it (Cohen et al., 2011). Reflexivity informs positionality. It requires an explicit selfconsciousness and self-assessment by the researcher about their views and positions and how these might, may, or have, directly or indirectly influenced the design, execution, and interpretation of the research data findings (Greenbank, 2003, May \& Perry, 2017). Reflexivity necessarily requires sensitivity by the researcher to their cultural, political, and social context (Bryman, 2016) because the individual's ethics, personal integrity, and social values, as well as their competency, influence the research process (Greenbank, 2003, Bourke, 2014). As a way of researchers commencing a reflexive approach to their work Malterud (2001, p.484) suggests that

Reflexivity starts by identifying preconceptions brought into the project by the researcher, representing previous personal and professional experiences, pre-study beliefs about how things are and what is to be investigated, motivation and qualifications for exploration of the field, and perspectives and theoretical foundations related to education and interests.

It is important for new researchers to note that their values can, frequently, and usually do change over time. As such, the subjective contextual aspects of a researcher's positionality or 'situatedness' change over time (Rowe, 2014). Through using a reflexive approach, researchers should continually be aware that their positionality is never fixed and is always situation and context-dependent. Reflexivity is an essential process for informing developing and shaping positionality, which may clearly articulated.

\section{Positionality and its affect on the research process}

It is essential for new researchers to acknowledge that their positionality is unique to them and that 
it can impact all aspects and stages of the research process. As Foote and Bartell (2011, p.46) identify

The positionality that researchers bring to their work, and the personal experiences through which positionality is shaped, may influence what researchers may bring to research encounters, their choice of processes, and their interpretation of outcomes.

Positionality, therefore, can be seen to affect the totality of the research process. It acknowledges and recognizes that researchers are part of the social world they are researching and that this world has already been interpreted by existing social actors. This is the opposite of a positivistic conception of objective reality (Cohen et al., 2011; Grix, 2019). Positionality implies that the social-historical-political location of a researcher influences their orientations, i.e., that they are not separate from the social processes they study. Simply stated, there is no way we can escape the social world we live in to study it (Hammersley \& Atkinson, 1995; Malterud, 2001). The use of a reflexive approach to inform positionality is a rejection of the idea that social research is separate from wider society and the individual researcher's biography. A reflexive approach suggests that, rather than trying to eliminate their effect, researchers should acknowledge and disclose their selves in their work, aiming to understand their influence on and in the research process. It is important for new researchers to note here that their positionality not only shapes their work but influences their interpretation, understanding, and, ultimately, their belief in the truthfulness and validity of other's research that they read or are exposed to. It also influences the importance given to, the extent of belief in, and their understanding of the concept of positionality.

Open and honest disclosure and exposition of positionality should show where and how the researcher believes that they have, or may have, influenced their research. The reader should then be able to make a better-informed judgment as to the researcher's influence on the research process and how 'truthful' they feel the research data is. Sikes (2004, p.15) argues that

It is important for all researchers to spend some time thinking about how they are paradigmatically and philosophically positioned and for them to be aware of how their positioning -and the fundamental assumptions they hold might influence their research related thinking in practice. This is about being a reflexive and reflective and, therefore, a rigorous researcher who can present their findings and interpretations in the confidence that they have thought about, acknowledged and been honest and explicit about their stance and the influence it has had upon their work.

For new researchers doing this can be a complex, difficult, and sometimes extremely time-consuming process. Yet, it is essential to do so. Sultana (2007, p.380), for example, argues that it is "critical to pay attention to positionality, reflexivity, the production of knowledge... to undertake ethical research". The clear implication being that, without reflexivity on the part of the researcher, their research may not be conducted ethically. Given that no contemporary researcher should engage in unethical research (BERA, 2018), reflexivity and clarification of one's positionality may, therefore, be seen as essential aspects of the research process.

\section{Finding your Positionality}

Savin-Baden \& Major (2013) identify three primary ways that a researcher may identify and develop their positionality. Firstly, locating themselves about the subject, i.e., acknowledging personal positions that have the potential to influence the research. Secondly, locating themselves about the participants, i.e., researchersindividually considering how they view themselves, as well as how others view them, while at the same time acknowledging that as individuals they may not be fully aware of how they and others have constructed their identities, and recognizing that it may not be possible to do this without considered in-depth thought and critical analysis. Thirdly, locating themselves about the research context and process, i.e., acknowledging that research will necessarily be influenced by themselves and by the research context. To those, I would add a fourth component; that of time. Investigating and clarifying one's positionality takes time. New researchers should recognize that exploring their positionality and writing a 
positionality statement can take considerable time and much 'soul searching'. It is not a process that can be rushed.

Engaging in a reflexive approach should allow for a reduction of bias and partisanship (Rowe, 2014). However, it must be acknowledged by novice researchers that, no matter how reflexive they are, they can never objectively describe something as it is. We can never objectively describe reality (Dubois, 2015). It must also be borne in mind that language is a human social construct. Experiences and interpretations of language are individually constructed, and the meaning of words is individually and subjectively constructed (von-Glaserfield, 1988). Therefore, no matter how much reflexive practice a researcher engages in, there will always still be some form of bias or subjectivity. Yet, through exploring their positionality, the novice researcher increasingly becomes aware of areas where they may have potential bias and, over time, are better able to identify these so that they may then take account of them. (Ormston et al., 2014) suggest that researchers should aim to achieve 'empathetic neutrality,' i.e., that they should

Strive to avoid obvious, conscious, or systematic bias and to be as neutral as possible in the collection, interpretation, and presentation of data...[while recognizing that] this aspiration can never be fully attained - all research will be influenced by the researcher and there is no completely 'neutral' or 'objective' knowledge.

\section{Positionality Statements and Novice Researchers}

Regardless of how they are positioned in terms of their epistemological assumptions, it is crucial that researchers are clear in their minds as to the implications of their stance, that they state their position explicitly (Sikes, 2004).

Positionality is often formally expressed in research papers, masters-level dissertations, and doctoral theses via a 'positionality statement,' essentially an explanation of how the researcher developed and how they became the researcher they are then. For most people, this will necessarily be a fluid statement that changes as they develop both through conducting a specific research project and throughout their research career. It is common for a novice researcher's positionality to change during a longer research project, such as one undertaken for a Ph.D.

Agood strong positionality statement will typically include a description of the researcher's lenses (such as their philosophical, personal, theoretical beliefs and perspective through which they view the research process), potential influences on the research (such as age, political beliefs, social class, race, ethnicity, gender, religious beliefs, previous career), the researcher's chosen or pre-determined position about the participants in the project (e.g., as an insider or an outsider), the research-project context and an explanation as to how, where, when and in what way these might, may, or have, influenced the research process (Savin-Baden \& Major, 2013). Producing a good positionality statement takes time, considerable thought, and critical reflection.

It is particularly important for novice researchers to adopt a reflexive approach and recognize that "The inclusion of reflective accounts and the acknowledgment that educational research cannot be value-free should be included in all forms of research" (Greenbank, 2003). Yet new researchers also need to realize that reflexivity is not a panacea that eradicates the need for awareness of the limits of self-reflexivity. Reflexivity can help to clarify and contextualize one's position about the research process for both the researcher, the research participants, and readers of research outputs. Yet, it is not a guarantee of more honest, truthful, or ethical research. Nor is it a guarantee of good research (Delamont, 2018). No matter how critically reflective and reflexive one is, aspects of the self can be missed, not known, or deliberately hidden, see, for example, Luft and Ingham's (1955) Johari Window - the 'blind area' known to others but not to oneself and the 'hidden area,' not known to others and not known to oneself. There are always areas of ourselves that we are not aware of, areas that only other people are aware of, and areas that no one is aware of. One may also, particularly in the early stages of reflection, not be as honest with one's self as one needs to be (Holmes, 2019).

Novice researchers should realize that, right from the very start of the research process, that their positionality will affect their research and will impact 
on their understanding, interpretation, acceptance, and belief, or non-acceptance and disbelief of other's research findings. It will also influence their views about reflexivity and the relevance and usefulness of adopting a reflexive approach and articulating their positionality. Each researcher's positionality affects the research process, and their outputs as well as their interpretation of other's research. (Smith, 1999) neatly sums this up, suggesting that "Objectivity, authority and validity of knowledge is challenged as the researcher's positionality... is inseparable from the research findings".

\section{The Insider-Outsider Positionality Debate}

Having discussed positionality and reflexivity, the new researcher should now be aware of their importance. I now briefly turn to the insider-outsider dialectic in ethnography, because the position of the researcher as being an insider or an outsider to the culture being studied and, both, whether one position provides the researcher with an advantageous position compared with the other, and its effect on the research process (Hammersley 1993 and Weiner et al. 2012) has been, and remains, a key debate. It is of relevance to all qualitative researchers, regardless of whether they are an ethnographer. The insideroutsider debate has become increasingly important because researchers frequently come from different backgrounds to those where they engage in research and to those who they engage in research with (Manohoe et al. 2017).

Ontologically the insider perspective is usually referred to as an emic account while the outsider perspective as an etic one. The terms refer to different ontological positions. An emic description or the insider's view of reality (Fetterman, 2008) is situated within a cultural relativist perspective, recognizing behavior and actions as being relative to the person's culture and the context in which that behavior or action is both rational and meaningful within that culture. It uses terminology that is meaningful to and from the perspective of a person from within the culture whose beliefs and behaviors are being studied. So, for example, interview transcriptions would include verbatim colloquial language, spelling, and grammar. Prior theories and assumptions are discarded or disregarded so that the true 'voice' of the research participants may be heard. An etic account is situated within a realist perspective, attempting to describe differences across cultures in terms of a general external standard and from an ontological position that assumes a pre-defined reality in respect of the researcher subject relationship (Nagar \& Geiger, 2007). Etic accounts aim to be culturally neutral (i.e., independent of culturally specific terminology or references), using and testing pre-existing theory and are written in terminology that is appropriate to a community of external scientific observers or scholars rather than those who are within the culture. So, for example, interview transcription would exclude colloquial language, and grammar and spelling would be corrected. Ontologically an etic position operates from the assumption that objective knowledge relies on the degree to which researchers can detach themselves from the prejudices of the social groups they study (Kusow, 2003).

The emic-etic divide is not limited to the research output, but is central to the process of conducting research. While the terms emic and etic refer to ontological positions, the terms 'insider' and 'outsider' also refer to whether a person is an actual insider or outsider to the culture under investigation, yet not necessarily that they are operating from an emic or etic position. By that, I mean that one can aim to adopt an etic ontological position but be an insider to the culture being studied, and vice versa. Though it is recognized that aiming to adopt a position is not the same as having that position, and it is questionable whether it is genuinely possible to do that.

\section{The Insider-Outsider Debate: Does Either Provide an Advantage?}

One area of debate regarding the insideroutsider position is that of whether or not being an insider to the culture positions the researcher more, or less, advantageously than an outsider. Epistemologically this is concerned with whether and how it is possible to present information accurately and truthfully. Merton's long-standing definition of insiders and outsiders is that "Insiders are the members of specified groups and collectives or occupants of specified social statuses: Outsiders are non-members" (Merton, 1972). Others identify 
the insider as someone whose personal biography (gender, race, skin-color, class, sexual orientation and so on) gives them a 'lived familiarity' with and a priori knowledge of the group being researched. At the same time, the outsider is a person/researcher who does not have any prior intimate knowledge of the group being researched (Griffith, 1998, cited in Mercer, 2007).

There are various lines of the argument put forward to emphasize the advantages and disadvantages of each position. In its simplest articulation, the insider perspective essentially questions the ability of outsider scholars to competently understand the experiences of those inside the culture, while the outsider perspective questions the ability of the insider scholar to sufficiently detach themselves from the culture to be able to study it without bias (Kusow, 2003). Space precludes a detailed consideration of every one of the aspects associated with the benefits and drawbacks of the insider-outsider duality, and with concerns of specific research lenses such as feminist and post-colonial positions. For a more extensive discussion, see (Merton, 1972). The main arguments are outlined below.

Advantages of an insider position include: (1) easier access to the culture being studied, as the researcher is regarded as being 'one of us' (Sanghera \& Bjokert 2008), (2) the ability to ask more meaningful or insightful questions (due to possession of a priori knowledge), (3) the researcher may be more trusted so may secure more honest answers, (4) the ability to produce a more truthful, authentic or 'thick' description (Geertz, 1973) and understanding of the culture, (5) potential disorientation due to 'culture shock' is removed or reduced, and (6) the researcher is better able to understand the language, including colloquial language, and non-verbal cues.

Disadvantages of an insider position include: (1) the researcher may be inherently and unknowingly biased, or overly sympathetic to the culture, (2) they may be too close to and familiar with the culture (a myopic view), or bound by custom and code so that they are unable to raise provocative or taboo questions, (3) research participants may assume that because the insider is 'one of us' that they possess more or better insider knowledge than they do, (which they may not) and that their understandings are the same (which they may not be). Therefore information which should be 'obvious' to the insider, may not be articulated or explained, (4) an inability to bring an external perspective to the process, (5) 'dumb' questions which an outsider may legitimately ask, may not be able to be asked (Naaek et al. 2010), and (6) respondents may be less willing to reveal sensitive information than they would be to an outsider who they will have no future contact with.

Unfortunately, it is the case that each of the above advantages can, depending upon one's perspective, be equally viewed as being disadvantages, and each of the disadvantages as being advantages, so that "The insider's strengths become the outsider's weaknesses and vice versa" (Merriam et al., 2001, p.411). Whether either position offers an advantage over the other is questionable. (Hammersley 1993) for example, argues that there are "No overwhelming advantages to being an insider or outside" but that each position has both advantages and disadvantages, which take on slightly different weights depending on the specific circumstances and the purpose of the research. Similarly, Mercer (2007) suggests that it is a 'double-edged sword' in that what is gained in one area may be lost in another, for example, detailed insider knowledge may mean that the 'bigger picture' is not seen.

There is also an argument that insider or outsider as opposites may be an artificial construct. There may be no clear dichotomy between the two positions (Herod, 1999), the researcher may not be either an insider or an outsider, but the positions can be seen as a continuum with conceptual rather than actual endpoints (Christensen \& Dahl, 1997, cited in Mercer, 2007). Similarly, Mercer (ibid. p.1) suggests that

The insider/outsider dichotomy is, in reality, a continuum with multiple dimensions and that all researchers constantly move back and forth along several axes, depending upon time, location, participants, and topic.

I would argue that a researcher may inhabit multiple positions along that continuum at the same time. Merton (1972, p.28) argues that

Sociologically speaking, there is nothing fixed about the boundaries separating Insiders from 
Outsiders. As situations involving different values arise, different statuses are activated, and the lines of separation shift.

Traditionally emic and etic perspectives are "Often seen as being at odds - as incommensurable paradigms" (Morris et al. 1999 p.781). Yet the insider and outsider roles are essentially products of the particular situation in which research takes place (Kusow, 2003). As such, they are both researcher and context-specific, with no clearly -cut boundaries. And as such may not be a divided binary (Mullings, 1999, Chacko, 2004). Researchers may straddle both positions; they may be simultaneously and insider and an outsider (Mohammed, 2001). For example, a mature female Saudi Ph.D. student studying undergraduate students may be an insider by being a student, yet as a doctoral student, an outsider to undergraduates. They may be regarded as being an insider by Saudi students, but an outsider by students from other countries; an insider to female students, but an outsider to male students; an insider to Muslim students, an outsider to Christian students; an insider to mature students, an outsider to younger students, and so on. Combine these with the many other insider-outsider positions, and it soon becomes clear that it is rarely a case of simply being an insider or outsider, but that of the researcher simultaneously residing in several positions. If insiderness is interpreted by the researcher as implying a single fixed status (such as sex, race, religion, etc.), then the terms insider and outsider are more likely to be seen by them as dichotomous, (because, for example, a person cannot be simultaneously both male and female, black and white, Christian and Muslim). If, on the other hand, a more pluralistic lens is used, accepting that human beings cannot be classified according to a single ascribed status, then the two terms are likely to be considered as being poles of a continuum (Mercer, 2007). The implication is that, as part of the process of reflexivity and articulating their positionality, novice researchers should consider how they perceive the concept of insideroutsiderness- as a continuum or a dichotomy, and take this into account.

It has been suggested (e.g., Ritchie, et al. 2009, Kirstetter, 2012) that recent qualitative research has seen a blurring of the separation between insiderness and outsiderness and that it may be more appropriate to define a researcher's stance by their physical and psychological distance from the research phenomenon under study rather than their paradigmatic position. Yet for novice researchers identifying their psychological distance from the research participants may be considerably difficult to do, and it, in practice, often changes as the research project progresses, and they get to get to know and develop a deeper understanding of the participants. The implication is that ongoing reflexivity throughout the research is necessary.

\section{Researcher Positionality and the Insider- Outsider: An Example from the Literature}

To help novice researchers better understand and reflect on the insider-outsider debate, reference will be made to a paper by Herod (1999) "Reflections on interviewing foreign elites, praxis, positionality, validity and the cult of the leader". This has been selected because it discusses the insider-outsider debate from the perspective of an experienced researcher who questions some of the assumptions frequently made about insider and outsiderness. Novice researchers who wish to explore insideroutsiderness in more detail may benefit from a thorough reading of this work along with those by Chacko (2004), and Mohammed, (2001). For more in-depth discussions of positionality, see (Clift et al. 2018).

Herod's paper questions the epistemological assumption that an insider will necessarily produce 'true' knowledge, arguing that research is a social process in which the interviewer and interviewee participate jointly in knowledge creation. He posits three issues from the first-hand experience, which all deny the duality of simple insider-outsider positionality. Firstly, the researcher's ability to consciously manipulate their positionality, secondly that how others view the researcher may be very different from the researcher's view, and thirdly, that positionality changes over time.

In respect of the researcher's ability to consciously manipulate their positionality he identifies that he deliberately presents himself in different ways in different situations, for example, presenting himself as "Dr." when corresponding 
with Eastern European trade unions as the title conveys status, but in America presenting himself as a teacher without a title to avoid being viewed as a "disconnected academic in my ivory tower" (ibid. p.321). Similarly, he identifies that he often 'plays up' his Britishness, emphasizing outsiderness because a foreign academic may, he feels, be perceived as being 'harmless' when compared to a domestic academic. Thus interviewees may be more open and candid about certain issues.

In respect of how others view the researcher's positionality differently from the researcher's view of themselves Herod identifies that his work has involved situations where objectively he is an outsider, and perceives of himself as such (i.e., is not a member of the cultural elite he is studying) but that others have not seen him as being an outsiderciting an example of research in Guyana where his permission to interview had been pre-cleared by a high-ranking government official, leading to the Guyanese trade union official who collected him from the airport to regard him as a 'pseudo insider,' inviting him to his house and treating him as though he were a member of the family. This, Herod indicates, made it more difficult for him to research than if he had been treated as an outsider.

Discussing how positionality may change over time, Herod argues that a researcher who is initially viewed as being an outsider will, as time progresses. More contact and discussion takes place, increasingly be viewed as an insider due to familiarity. He identifies that this particularly happens with followup interviews, in his case when conducting follow up interviews over three years, each a year apart in the Czech Republic; each time he went, the relationship was "more friendly and less distant" (ibid. p.324). Based on his experiences, Herod identifies that if we believe that the researcher and interviewee are co-partners in the creation of knowledge then the question as to whether it even really makes sense or is useful to talk about a dichotomy of insider and outsider remains, particularly given that the positionality of both may change through and across such categories over time or depending upon what attributes of each one's identities are stressed(ibid. p.325).

\section{Summary and Concluding Remarks}

Positionality is integral to the process of qualitative research, as is the researcher's awareness of the lack of stasis of our own and other's positionality. For new postgraduate researchers identifying and clearly articulating their positionality in respect of the project being undertaken may not be a simple or quick process, yet it is essential to do so. Novice researchers should engage in reflexivity to develop and embrace their positionality, recognizing that it is not fixed and will necessarily change over time. As part of this process, they should pay particular attention to their multiple positions as an insider or outsider to the research participants and setting(s) where the work is conducted, acknowledging there may be both advantages and disadvantages that may have far-reaching implications for the process of data gathering and interpretation. New researchers should also acknowledge that, while engaging in reflexive practice and articulating their positionality is not a guarantee of higher quality research, that through doing so, they should become a better researcher.

\section{References}

Atkinson, Paul and Martya Hammersley. "Ethnography and Participant Observation." The Handbook of Qualitative Research, edited by Denzin, N.K. and Yvonna S Lincoln, Sage, 1994, pp. 248-261.

Bahari, Siti Fatimah. "Qualitative versus Quantitative Research Strategies: Contrasting Epistemological and Ontological Assumptions." Jurnal Teknologi, vol. 52, 2010, pp. 17-28.

Balarin, Maria. "Using Theory in Social Research: Reflections on a Doctoral Study." Knowledge Values and Educational Policy: A Critical Perspective, edited by Daniels, et al, Routledge, 2009.

Bourke, Brian. "Positionality: Reflecting on the Research Process." The Qualitative Report, vol. 19, no. 33, 2014, pp. 1-9.

Bryman, Alan. Social Research Methods, Oxford University Press, 2016.

Chacko, Elizabeth. "Positionality and Praxis: Fieldwork Experiences in Rural India." Singapore Journal of Tropical Geography, 
vol. 25 , no. 1, 2004, pp. 51-63.

Chiseri-Strater, Elizabeth. "Turning in upon Ourselves: Positionality, Subjectivity and Reflexivity in Case Study and Ethnographic Research." Ethics and Representation in Qualitative Studies of Literacy, edited by Mortensen, Peter and Gesa E. Kirsch, National Council of Teachers of English, 1996, pp. 115-133.

Christensen, Donna Hendrickson and Carla M. Dahl. "Rethinking Research Dichotomies." Family \& Consumer Sciences Research Journal, vol. 25 , no. 3, 1997, pp. 269-285.

Cohen, Louis, et al. Research Methods in Education, Routledge, 2011.

Delamont, Sara. "Truth is not Linked to Political Virtue: Problems with Positionality." How do we belong? Researcher Positionality within Qualitative Inquiry, edited by Clift, Bryan et al., The Fourth Annual Qualitative Research Symposium, University of Bath, 2018.

Dubois, Michel. "Ideology, Sociology of." International Encyclopedia of the Social \& Behavioural Sciences 2nd ed., edited by Wright, J.D., Elsevier, 2015, pp. 573-587.

Ethical Guidelines for Educational Research, British Educational Research Association, 2018.

Fetterman, David. "Emic/Etic Distinction." The Sage Encyclopedia of Qualitative Research Methods, edited by Given, Lisa M., Sage, 2008.

Foote, Mary Q. and Tonya Gau Bartell. "Pathways to Equity in Mathematics Education: How Life Experiences Impact Researcher Positionality." Educational Studies in Mathematics, vol. 78, 2011, pp. 45-68.

Geertz, Clifford. The Interpretation of Cultures, Basic Books, 1973.

Grix, Jonathan. The Foundations of Research, Macmillan International, 2019.

Hammersley, Martyn. "On the Teacher as Researcher." Educational Action Research, vol. 1, no. 3, 1993, pp. 425-445.

Hammersley, Martyn and Paul Atkinson. Ethnography Principles in Practice, Routledge, 1995.
Herod, Andrew. "Reflections on Interviewing Foreign Elites: Praxis, Positionality, Validity and the cult of the Insider." Geoforum, vol. 30, 1999, pp. 313-327.

Holmes, A.G. "Constructivist Learning in University Undergraduate Programmes. Has Constructivism been fully embraced? Is there Clear Evidence that Constructivist Principles have been Applied to all Aspects of Contemporary University Undergraduate Study?" Shanlax International Journal of Education, vol. 8, no. 1, 2019, pp. 7-15.

How do we belong? Researcher Positionality within Qualitative Inquiry, edited by Clift, Bryan et al., The Fourth Annual Qualitative Research Symposium, University of Bath, 2018.

Jansson, David. "The Head vs. the Gut: Emotions, Positionality, and the Challenges of Fieldwork with a Southern Nationalist Movement." Geoforum, vol. 41, no. 1, 2010, pp. 19-22.

Kirstetter, Katie. "Insider, Outsider or Somewhere in between: The Impact of Researchers' Identities on the Community based Research Process." Journal of Rural Social Sciences, vol. 27, no. 2, 2012, pp. 99-117.

Kusow, Abdi M. "Beyond Indigenous Authenticity: Reflections on the Insider/Outsider Debate in Immigration Research." Symbolic Interaction, vol. 26, no. 4, 2003, pp. 591-599.

Malterud, Kirsti. "Qualitative Research; Standards, Challenges and Guidelines." The Lancet, vol. 358, 2001, pp. 483-488.

Marsh, David, et al. "A Skin not a Sweater: Ontology and Epistemology in Political Science." Theory and Methods in Political Science, edited by Lowndes, V. et al., PalgraveMacmillan Education, 2017.

May, Tim and Beth Perry. Reflexivity: The Essential Guide, Sage, 2017.

Mercer, Justine. "The Challenges of Insider Research in Educational Institutions: Wielding a Double-edged Sword and Resolving Delicate Dilemmas." Oxford Review of Education, vol. 33, no. 1, 2007, pp. 1-17.

Merriam, Sharan B. et al. "Power and Positionality: Negotiating Insider/Outsider Status within and Across Cultures." International Journal 
of Lifelong Education, vol. 20, no. 5, 2001.

Merton, Robert K. "Insiders and Outsiders: A Chapter in the Sociology of Knowledge.' American Journal of Sociology, vol. 78, no. 1, 1972, pp. 9-47.

Mohammad, Robina. "Insiders and/or Outsiders: Positionality, Theory and Praxis." Qualitative Methods for Geographers: Issues and Debates, edited by Limb, Melanie and Claire Dwyer, Oxford University Press, 2001, pp. 101-117.

Morris, Michael W., et al. "Views from Inside and Outside: Integrating Emic and Etic Insights about Culture and Justice Judgement." Academy of Management Review, vol. 24, no. 4, 1999, pp. 781-796.

Mullings, Beverley. "Insider or Outsider, both or neither: Some Dilemmas of Interviewing in a Cross-cultural Setting." Geoforum, vol. 30, no. 4, 1999, pp. 337-350.

Naaeke, Anthony, et al. "Insider and Outsider Perspective in Ethnographic Research." Proceedings of the 68th New York State Communication Association, 2010.

Nagar, Richa and Susan Geiger. "Reflexivity and Positionality in Feminist Fieldwork Revisited." Policy and Practice in Economic Geography, edited by Tickell, Adam, et al. Sage, 2007.

Newby, Peter. Research Methods for Education. Pearson, 2010.

Ormston, Rachel, et al. "The Foundations of Qualitative Research." Qualitative Research Practice: A guide for Social Science Students and Researchers, edited by Ritchie, Jane, et al., Sage, 2014.

Ritchie, Jan, et al. "Insider-Outsider Positions in Health-development Research: Reflections for Practice." Development in Practice, vol. 19, no. 1, 2009, pp. 106-112.

Rolfe, Gary. "In response to Porter S. Validity, Trustworthiness and Rigour: Reasserting Realism in Qualitative Research." Journal of
Advanced Nursing, vol. 60, no. 1, 2007.

Rowe, Wendy E. "Positionality." The Sage Encyclopedia of Action Research, edited by Coghlan, David and Mary Brydon-Miller, Sage, 2014.

Sanghera, Gurchathen S. and Suruchi ThaparBjorkert. "Methodological Dilemmas: Gatekeepers and Positionality in Bradford." Ethnic and Racial Studies, vol. 31, no. 3, 2008, pp. 543-562.

Savin-Baden, Maggi and Claire Howell Major. Qualitative Research: The Essential Guide to Theory and Practice, Routledge, 2013.

Scotland, James. "Exploring the Philosophical Underpinnings of Research: Relating Ontology and Epistemology to the Methodology and Methods of the Scientific, Interpretive, and Critical Research Paradigms." English Language Teaching, vol. 5, no. 9, 2012, pp. 9-16.

Sikes, Pat. "Methodology, Procedures and Ethical Concerns." Doing Educational Research: A Guide for First Time Researchers, edited by Opie, Clive, Sage, 2004.

Smith, Linda Tuhiwai. Decolonising Methodologies: Research and Indigenous Peoples, University of Otago Press, 1999.

Sultana, Farhana. "Reflexivity, Positionality and Participatory Ethics: Negotiating Fieldwork Dilemmas in International Research." $A C M E$ : An International E-Journal for Critical Geographies, vol. 6, no. 3, 2007, pp. 374-385.

Von-Glaserfield, Ernst. "Why Constructivism must be Radical." Constructivism and Education, edited by Larochelle, Marie, et al., Cambridge University Press, Cambridge, 1988.

Weiner-Levy, Naomi and Sarab Abu RabiaQueder. "Researching my People, Researching the "other": Field Experiences of two Researchers along Shifting Positionalities." Quality \& Quantity, vol. 46, no. 4, 2012, pp. 1151-1166. Wellington, Jerry. Succeeding with Your Doctorate, Sage, 2005.

\section{Author Details}

Andrew Gary Darwin Holmes, School of Education, University of Hull, Hull, England,

EmailID: a.g.holmes@hull.ac.uk. 